Pesq. Vet. Bras. 36(2):108-118, fevereiro 2016

DOI: $10.1590 /$ S0100-736X2016000200008

\title{
Utilização de plasma rico em plaquetas para estimulação da angiogênese em flape de padrão axial toracodorsal em coelhos (Oryctolagus cuniculus) $^{1}$
}

\author{
Josiane M. Pazzini²*, Andrigo B. De Nardi², Rafael R. Huppes², Ana P. Gering², Marília \\ G.P.A. Ferreira² ${ }^{2}$ Camila P.B, Silveira ${ }^{2}$, Mayara C. Luzzi $^{2}$ e João A. Oliveira ${ }^{3}$
}

\begin{abstract}
Pazzini J.M., De Nardi A.B., Huppes R.R., Gering A.P., Ferreira M.G.P.A., Silveira C.P.B., Luzzi M.C. \& Oliveira J.A. 2016. [Use of platelet rich plasma to stimulate angiogenesis in the thoracodorsal axial pattern flap in rabbits (Oryctolagus cuniculus).] Utilização de plasma rico em plaquetas para estimulação da angiogênese em flape de padrão axial toracodorsal em coelhos (Oryctolagus cuniculus). Pesquisa Veterinária Brasileira 36(2):108118. Departamento de Clínica e Cirurgia Veterinária, Faculdade de Ciências Agrárias e Veterinárias, Universidade Estadual Paulista, Campus Jaboticabal, Via de Acesso Paulo Donatto Castellane s/n, Jaboticabal, SP 14884.900, Brazil, E-mail: josipazzini@hotmail.com

Wounds of large tracts with loss of tissue viability and delayed healing by secondary intention are cases where it is necessary the use of reconstructive surgical techniques. The platelet rich plasma (PRP) is a product with a higher platelet concentration, adjuvant in the healing process of reconstructive surgeries, assisting in the processes of hemostasis and stimulation of angiogenesis. Thus, a study was devised to assess the efficacy of the gel produced from the platelet rich plasma (PRP) in the forward axial flaps thoracodorsal pattern in rabbits to evaluate the ability to promote the integration of the flap the recipient bed. We used 30 white rabbits New Zealand, separated into two groups of 15 animals, comprising the platelet rich plasma groups (GPRP), in which we used the gel before the synthesis of the surgical wound, and control (CG), in which only saline was used. To obtain the PRP, the blood was collected from the animals, was determined and the platelet count before preparation of the gel. At the beginning and end of the experiment the animals were weighed for analysis of average weight gain. After surgery began macroscopic in the 3rd, 7th and 14th day reviews, and we assessed the presence or absence of exudate, skin integrity, edema, redness and necrosis. After this step, yielded the material for the manufacture of surgical wound, followed by microscopic histological slides. We evaluated vascular proliferation, presence of polymorphonuclear and mononuclear cells, fibroblast proliferation, collagen deposition, reepithelialization and hemorrhage. The data were subjected to statistical analysis (Student $\mathrm{t}$ test, t paired, and Kruskal Wallis test, and $p<0.05$ ). The average weight gain was not significant between the groups; platelet concentration in the final sample of PRP was significantly higher when compared with the original; exudate and necrosis were significantly higher in the control group compared to PRP group, vascular proliferation and reepithelialization were significantly greater in PRP group, whereas the presence of mononuclear cells, polymorphonuclear cells, proliferation of fibroblasts, collagen and hemorrhage were not significant between groups. Obtained on the third day, as the difference significantly greater exudate variable in the control group compared to the PRP group; on
\end{abstract}

\footnotetext{
${ }^{1}$ Recebido em 14 de fevereiro de 2015.

Aceito para publicação em 22 de setembro de 2015.

${ }^{2}$ Departamento de Clínica e Cirurgia Veterinária, Faculdade de Ciências Agrárias e Veterinárias de Jaboticabal (FCAV), Universidade Estadual Paulista (Unesp), Via de Acesso Professor Paulo Donato Castellane s/n, Jaboticabal, SP 14884-900, Brasil. E-mails: E-mails: andrigobarboza@
}

yahoo.com.br, rafaelhuppes@hotmail.com, geringbr@yahoo.com.br, mar-pops1@hotmail.com, bibiagarvana@gmail.com, mayaraluzzi@hotmail. com; *Autor para correspondência: josipazzini@hotmail.com

${ }^{3}$ Departamento de Estatística, FCAV-Unesp, Via de Acesso Professor Paulo Donato Castellane s/n, Jaboticabal, SP 14884-900. E-mail: jaoliv@ fcav.unesp. 
the seventh day exudate and flushing were significantly higher in the control group, and the fourteenth day exudate and integrity of the skin were significantly higher in the control group. The results of this study showed that the use of platelet rich plasma gel in the form of reconstructive surgery was able to stimulate angiogenesis in the wound favoring the healing process.

INDEX TERMS: Reconstructive surgery, thoracodorsal axial pattern flap, wound, revascularization, cicatrization, PRP, rabbit.

RESUMO.- Feridas de grandes extensões, com perda da viabilidade tecidual e retardo na cicatrização por segunda intenção são casos que se faz necessário o emprego de técnicas cirúrgicas reconstrutivas. 0 plasma rico em plaquetas (PRP) é um produto com maior concentração plaquetária, adjuvante no processo cicatricial de cirurgias reconstrutivas, auxiliando nos processos de hemostasia e estimulação da angiogênese. Dessa forma, delineou-se um estudo a fim de avaliar a eficácia do uso do gel produzido a partir do plasma rico em plaquetas (PRP) em flapes de avanço de padrão axial toracodorsal em coelhos, para avaliar a possibilidade de favorecer a integração do retalho no leito receptor. Utilizaram-se 30 coelhos da raça Nova Zelândia branco, separados em dois grupos de 15 animais, compreendendo os grupos plasma rico em plaquetas (GPRP), na qual empregou-se o gel antes da síntese da ferida cirúrgica, e controle (GC), na qual utilizou-se apenas solução fisiológica. Para obtenção do PRP, coletou-se sangue dos animais, e determinou-se a contagem plaquetária antes da preparação do gel. No início e término do experimento os animais foram pesados para posterior análise de ganho peso médio. Após o procedimento cirúrgico iniciou-se as avaliações

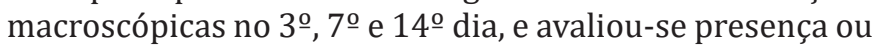
ausência de exsudato, integridade da pele, edema, rubor e necrose. Após esta etapa, coletou-se o material da ferida cirúrgica para confecção das lâminas histológicas e posterior avaliação microscópica. Avaliou-se a proliferação vascular, presença de células mononucleares e polimorfonucleares, proliferação fibroblástica, colagenização, reepitelização e hemorragia. Os dados obtidos foram submetidos à análise estatística (Teste t Student, t emparalhado, e Kruskall Walis, sendo $\mathrm{p}<0,05)$. 0 ganho de peso médio não foi significativo entre os grupos; a concentração plaquetária da amostra final do PRP foi significativamente maior quando comparada com a inicial; exsudato e necrose foram significativamente maior no grupo controle quando comparado ao grupo PRP; proliferação vascular e reepitelização foram significativamente maior no grupo PRP, enquanto que a presença de mononucleares, polimorfonucleares, proliferação de fibroblastos, colagenização e hemorragia não foram significativas entre os grupos. Obteve-se no terceiro dia, diferença significativamente maior quanto à variável exsudato no grupo controle quando comparado ao grupo PRP, no sétimo dia exsudato e rubor foram significativamente maior no grupo controle, e ao décimo quarto dia exsudato e integridade da pele foram significativamente maior no grupo controle. Os resultados obtidos neste estudo evidenciaram que a utilização do plasma rico em plaquetas na forma de gel em cirurgia reconstrutiva foi capaz de estimular a angiogênese na ferida favorecendo o processo de cicatrização.
TERMOS DE INDEXAÇÃO: Cirurgia reconstrutiva, flape de padrão axial toracodorsal, ferida, neo-vascularização, cicatrização, PRP, coelho.

\section{INTRODUÇÃO}

Segundo Pavletic (2007), o conhecimento anatômico da pele é fundamental no momento da aplicação de técnicas cirúrgicas reconstrutivas. Entretanto, em cães e gatos, a escolha pelo emprego de flapes cutâneos é dificultada, pois muitas vezes a neovascularização apresenta-se comprometida após a realização do procedimento cirúrgico. É importante ressaltar que a aplicação da mesma técnica em humanos apresenta resultados satisfatórios, devido a conformação anatômica dos vasos músculo cutâneos deslizarem-se perpendicularmente à superfície da pele e encontrarem-se em maior quantidade quando comparado com cães e gatos. Dessa forma, a grande vantagem de se empregar os flapes cutâneos é devido ao fato deles permitirem a cobertura imediata da região afetada e reduzirem o tempo de cicatrização do tecido, proporcionando ao paciente melhores resultados estéticos e funcionais (Hedlund 2005).

As feridas de grandes extensões provocadas por traumas, anormalidades congênitas e neoplasias, que apresentam a perda da viabilidade dos tecidos e demoram a cicatrizarem por segunda intenção, são casos onde se faz necessário o emprego de técnicas cirúrgicas reconstrutivas. Entretanto, o sucesso da técnica irá depender da extensão da lesão e a quantidade de estruturas comprometidas (Slatter 2007, Pavletic 2010).

Em muitos estudos, o plasma rico em plaquetas (PRP) é tido como produto adjuvante no processo cicatricial de cirurgias reconstrutivas, devido ao seu potencial auxílio nos processos de hemostasia e estimulação da formação de novos vasos sanguíneos (Nunes Filho et al. 2007, Vendramin et al. 2010).

O PRP é obtido por meio da centrifugação do sangue autógeno, que resulta em maior concentração de plaquetas em menor volume de plasma (Pagliosa \& Alves 2007, Sommeling et al. 2013). A comprovação da eficácia do uso do plasma rico em plaquetas já foi demostrada em vários estudos (Bauer et al. 2009, Silva et al. 2011, Vendruscolo et al. 2012, Garcez et al. 2013) e ainda pesquisadores buscam o conhecimento da eficácia dos efeitos biológicos do PRP quando aplicado em tecidos moles, osso e tegumento (Anitua 1999).

Objetivou-se avaliar a eficácia do uso do gel produzido a partir do plasma rico em plaquetas (PRP) em flapes de avanço de padrão axial toracodorsal. Bem como avaliar a angiogênese local onde o procedimento foi realizado, a redução da ocorrência de necrose na extremidade dos flapes e ainda avaliar a eficácia da fase reparação e integração do 
retalho no leito receptor em coelhos da raça Nova Zelândia Branco.

\section{MATERIAL E MÉTODOS}

Os procedimentos cirúrgicos deste estudo foram realizados no Hospital Veterinário "Governador Laudo Natel" da Faculdade de Ciências Agrárias e Veterinárias (FCAV), Universidade Estadual Paulista (Unesp), Câmpus de Jaboticabal. As lâminas destinadas à análise histológicas foram confeccionadas no Laboratório VetPat em Campinas, SP. 0 presente trabalho foi aprovado pelo Comitê de Ética no Uso de Animais (CEUA) da Universidade Estadual Paulista (Unesp), Câmpus de Jaboticabal ${ }^{4}$.

O modelo experimental utilizado para realização das cirurgias reconstrutivas foi o coelho (Oryctolagus cuniculus). Foram utilizados 30 coelhos da raça Nova Zelândia Branco, com a aproximadamente 170 dias de idade, fêmeas e peso médio de $3,45 \mathrm{~kg}$, provenientes de produtor especializado na criação da espécie. Os coelhos foram mantidos no biotério do Curso de Pós-graduação em Cirurgia Veterinária, em gaiolas individuais com dimensões de 80×50×35cm, obedecendo-se os princípios éticos em experimentação animal preconizados pelo Conselho Nacional de Experimentação Animal (CONCEA). Foi fornecido durante todo o experimento aos animais ração comercial ${ }^{5}$ própria para a espécie e água ad libitum.

Durante o período experimental os animais foram pesados no $1^{\circ}$ e no $14^{\circ}$ dia, para avaliar a diferença relacionada ao ganho de peso médio dos animais de cada grupo, a fim de verificar se o procedimento cirúrgico provocaria resposta orgânica ao trauma que repercutisse no estado geral dos animais.

Os animais foram separados em dois grupos de 15 animais cada, compreendendo os grupos plasma rico em plaquetas (GPRP) e controle (GC). Em todos os animais foram realizados flapes de avanço de padrão axial toracodorsal, sendo que no GPRP empregou-se o gel de plasma rico em plaquetas antes da síntese da ferida cirúrgica, e no GC, apenas foi utilizado solução fisiológica ${ }^{6}$.

Não foi necessário submeter os animais ao jejum alimentar e hídrico. 0 protocolo anestésico consistiu em Cloridrato de Clorpromazina $^{7}$, na dose de $0,5 \mathrm{mg} / \mathrm{kg}$, e Morfina $^{8}$, na dose de $0,5 \mathrm{mg} /$ $\mathrm{kg}$, diluídos na mesma seringa, por via intramuscular (IM) como medicação pré-anestésica. Após sedação, foram coletadas amostras de sangue dos 30 coelhos submetidos ao procedimento cirúrgico. As amostras de sangue do GC não foram submetidas ao preparo de PRP, apenas coletadas para não haver diferenças entres os grupos quanto ao volume de sangue corpóreo. Realizou-se tricotomia da região cervical para acesso das veias jugulares, e procedeu-se antissepsia com clorexidine e solução de álcool a $90 \%$. Os animais foram posicionados em decúbito esternal com o pescoço em extensão dorsal máxima para permitir a visualização adequada das veias jugulares. Procedeu-se venopunção e coleta de $8 \mathrm{~mL}$ de sangue, acondicionada em três tubos estéreis, dois com capacidade de $3,6 \mathrm{~mL}$ contendo citrato de sódio $^{9}$ (anticoagulante) destinados à preparação do PRP, e um terceiro tubo com capacidade de $1 \mathrm{~mL}$ contendo EDTA $^{10}$ (anticoagulante) foi preenchido com $0,8 \mathrm{ml}$ de sangue o qual foi destinado à contagem de plaquetas. Após determinar em máquina automática ${ }^{11}$ a contagem plaquetária dentro dos parâmetros fisiológicos para a espécie, deu-se início a preparação do PRP por outro integrante da equipe, enquanto o procedimento cirúrgico foi realizado.

O frasco com citrato de sódio foi empregado na produção do plasma rico em plaquetas (PRP) pelo protocolo de dupla centrifugação em centrífuga laboratorial comum ${ }^{12}$ conforme descrito por Morato (2013). Os tubos foram centrifugados com tampa fechada, à 1600 rotações por minuto (rpm) durante 10 minutos, resultando na separação de hemácias e plasma contendo leucócitos e plaquetas. Em capela de fluxo laminar ${ }^{13}$, os tubos eram destampados para que o plasma fosse pipetado e transferido para outro tubo estéril. 0 plasma era novamente centrifugado a 2000 rotações por minuto (RPM) por 10 minutos, resultando em duas partes de plasma: a superior, consistindo o plasma pobre em plaquetas (PPP) e a parte inferior, um botão plaquetário. 0 PPP foi descartado de modo que permanecesse apenas $1 \mathrm{ml}$ de PPP e botão plaquetário. Esse material foi levemente agitado para promover a ressuspensão das plaquetas, resultando assim na produção do plasma rico em plaquetas (PRP).

Ao término do processo de enriquecimento do plasma, a contagem da concentração de plaquetas foi realizada em máquina automática ${ }^{9}$, a partir de uma alíquota de $80 \mu \mathrm{L}$ da amostra do PRP. Ao término da contagem das plaquetas na amostra, com auxílio de seringa de $1 \mathrm{~mL}$, o PRP dentro do tubo estéril foi ativado por meio da adição de $0,3 \mathrm{~mL}$ de gluconato de cálcio ${ }^{14}$, no momento de sua utilização terapêutica, adquirindo assim, propriedades semelhantes a um gel, estando dessa forma, pronto para ser utilizado.

Em seguida, à coleta do sangue, realizou-se ampla tricotomia da face lateral esquerda do tórax e membro torácico ipisilateral. Após o término da tricotomia realizou-se venopunção da veia auricular dos pacientes com cateter $24^{15}$ para fluidoterapia de manutenção com solução de ringer lactato ${ }^{16}$, e procedeu-se indução anestésica com propofol ${ }^{17}$, na dose de $10 \mathrm{mg} / \mathrm{kg}$. Na sequência procedeu-se intubação orotraqueal com sonda de Magill de 3,0 mm de diâmetro, conectada ao aparelho de anestesia para fornecimento fluxo total de $1 \mathrm{~L} / \mathrm{min}$ de oxigênio a $100 \%$ por meio de circuito anestésico sem reinalação de gases ${ }^{18}$. Foi realizada anestesia geral inalatória com isofluorano ${ }^{19}$, na dose de $3 \%$, diluído em 100\% oxigênio.

Para a realização da ferida dermoepidérmica e demarcação do segmento de pele a ser retirado em região de cotovelo esquerdo, foi utilizada caneta cirúrgica ${ }^{20}$ (Fig.1A) e régua estéril para criar uma lesão de $4 \mathrm{~cm}$ de comprimento por $4 \mathrm{~cm}$ de largura, no formato de um quadrado. Com o auxílio de uma lâmina de bisturi $\mathrm{n}^{0} 15^{21}$ foi excisado o fragmento cutâneo de $16 \mathrm{~cm}^{2}, 1 \mathrm{~cm}$ acima e 3 $\mathrm{cm}$ abaixo da extremidade do olecrano (Fig.1B).

Logo após a realização da lesão do cotovelo, o procedimento de cirurgia reconstrutiva foi realizado, confeccionou-se o flape de padrão axial toracodorsal com caneta cirúrgica (Fig.1B), com o paciente em decúbito lateral, e o membro torácico em extensão, perpendicular ao tronco. 0 flape foi criado por ampla incisão cutânea

\footnotetext{
${ }^{4}$ Protocolo no. $028406 / 12$.

${ }^{5}$ Nature multivida coelho, Socil - Sgh Ind. e Com. Ltda, Descalvado, SP.

${ }^{6}$ Fisiológico 0,9\%, JP Indústria Farmacêutica S.A., Ribeirão Preto, SP.

${ }^{7}$ Clorpromazina ${ }^{\circledR}$, Cristália Produtos Químicos e Farmacêuticos, Itapira, SP.

${ }^{8}$ Dimorf, Cristália, Itapira, SP.

${ }^{9}$ Tubo BD vacutaneir ${ }^{\circledR}$ citrato de sódio, BD, São Paulo, SP.

10 Tubo pediátrico BD vacutaneir ${ }^{\circledR}$ EDTA, BD, São Paul, SP.

11 Poch, 100iV Diff, Médica Comércio Representações e Importações Ltda, Recife, PAE.

${ }^{12}$ Modelo 206 I centrifuge/Fanem ${ }^{\circledR}$, São Paulo, SP.

${ }^{13}$ Vecoflow Ltda, Modelo bio 12, Campinas, SP.

${ }^{14}$ Gluconato de cálcio $100 \mathrm{mg} / \mathrm{ml} /$ Hipolabor, Sabará, MG.

${ }^{15}$ Cateter BD Angiocath 24 - Becton, Dickinson Indústria Cirúrgica Ltda, Juiz de Fora, MG.

${ }^{16}$ Riger lactato, JP Indústria Farmacêutica S.A, Ribeirão Preto, SP.

${ }^{17}$ Diprivan, zeneca Farmacêutica do Brasil Ltda, São Paulo, SP.

${ }^{18}$ Ohmeda. mod. Excel 210SE, Datex Ohmeda, Miami, EUA (Processo FAPESP 97/10668-4).

${ }^{19}$ Isoflurine, Cristália, Itapira, SP.

${ }^{20}$ Skins, T Surgical Skin Marker, Batrik Medical Manufacturing Inc., Quebec, Canadá.

${ }^{21}$ Lâmina de bisturi N15, Solidor, São Paulo, SP.
} 


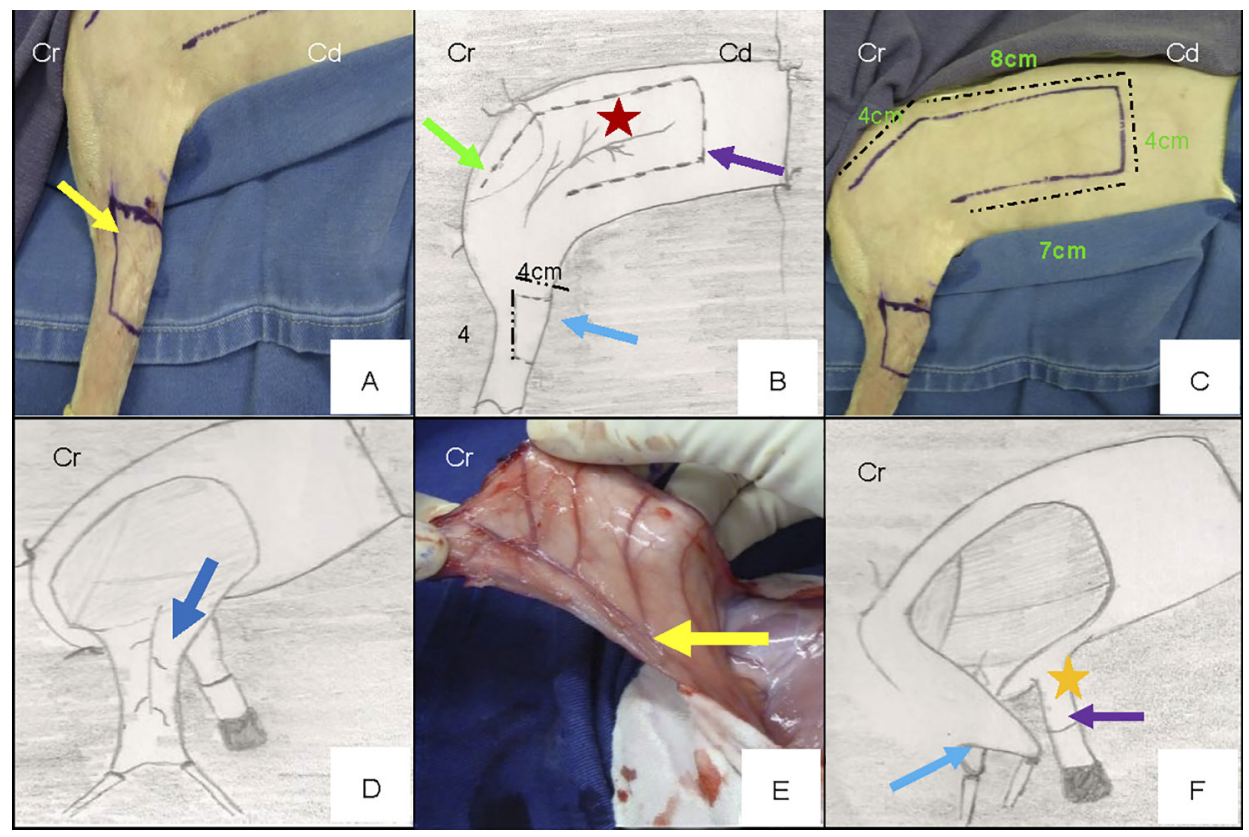

Fig.1. Esquema ilustrativo da diérese do procedimento cirúrgico de reconstrução realizado no Hospital Veterinário da Faculdade de Ciências Agrárias e Veterinárias (FCAV) da Unesp, Campus de Jaboticabal, 2013. (A) Demarcação do segmento de pele a ser retirado confeccionado com auxílio de caneta cirúrgica e régua estéril (seta). (B) Criação da lesão com $4 \mathrm{~cm}^{2}$, no formato de um quadrado, com $1 \mathrm{~cm}$ acima e $3 \mathrm{~cm}$ abaixo da extremidade do olecrano (seta azul); confecção do flape de padrão axial toracodorsal com caneta cirúrgica (seta roxa); localização da artéria e veia toracodorsal (asterisco) caudal à articulação escápulo-umeral (seta verde). (C) Finalização da marcação do flape formando um "L" invertido no tórax do lado esquerdo. (D) Suspensão do flape para iniciar a confecção do tubo de comunicação. (E) Presença da artéria e veia toracodorsal junto ao retalho criado (seta). (F) Mobilização do retalho com sua porção caudal (seta azul) até a porção distal (seta roxa) da ferida no cotovelo (asterisco).

em "L" invertido, com limites determinados de acordo com as referências anatômicas descrita na literatura (Fossum, 2007) e conforme a espécie, as quais foram previamente palpadas e demarcadas na pele do paciente com caneta cirúrgica. Para tal, foi estimada a localização da artéria e veia toracodorsal (Fig.1B) imediatamente caudal à articulação escápulo-umeral (Fig.1B). A partir deste ponto, seguindo em sentido dorsal, realizou-se duas incisões paralelas entre si: a primeira, $3 \mathrm{~cm}$ abaixo do processo espinhoso da coluna vertebral, iniciando sobre a espinha da escápula, estendendo-se 8 $\mathrm{cm}$ pararela a linha média dorsal, e a segunda iniciada $4 \mathrm{~cm}$ caudal a articulação do ombro e finalizada $7 \mathrm{~cm}$ caudal a lateral do tórax (Fig.1C). 0 flape foi finalizado formando um "L" invertido, e o limite considerado para profundidade da incisão, o qual determinou a espessura do flape, foi o músculo cutâneo do tronco. Suspendeu-se o flape para iniciar a confecção do tubo de comunicação (Fig.1D), era possível observar a presença da artéria e veia toracodorsal junto ao retalho criado (Fig.1E). O flape foi então mobilizado com sua porção caudal até a porção distal da ferida no cotovelo (Fig.1F) e acomodado de modo que se pudesse cobrir completamente a solução de continuidade oriunda da lesão induzida no cotovelo (Fig.2A).

Para realização da síntese cirúrgica das bordas da ferida à do flape no leito receptor utilizou-se náilon $4-0^{22}$, em padrão simples separado. Não foi realizado suturas subcutâneas. O tubo de comunicação constituído da artéria e veia toracodorsal que interligava o leito doador com o leito receptor foi aproximado entre si com padrão de sutura simples separado utilizando náilon 4-0 (Fig.2B). A ferida do leito doador no tórax foi submetida à redução de espaço morto com fio absorvível sintético monofilamentar poliglecaprone $4.0^{23}$ (Fig.2C) e dermorrafia com náilon 4-07, em padrão de sutura Wolf (Fig.2D).

\footnotetext{
${ }^{22}$ Nylon monofilamentar, Point Suture do Brasil Indústria de Fios Cirúrgicos Ltda, Fortaleza, CE.

${ }^{23}$ Caprofyl, ETHICON ${ }^{\top M}$ Johnson \& Johnson, São José dos Campos, SP.
}

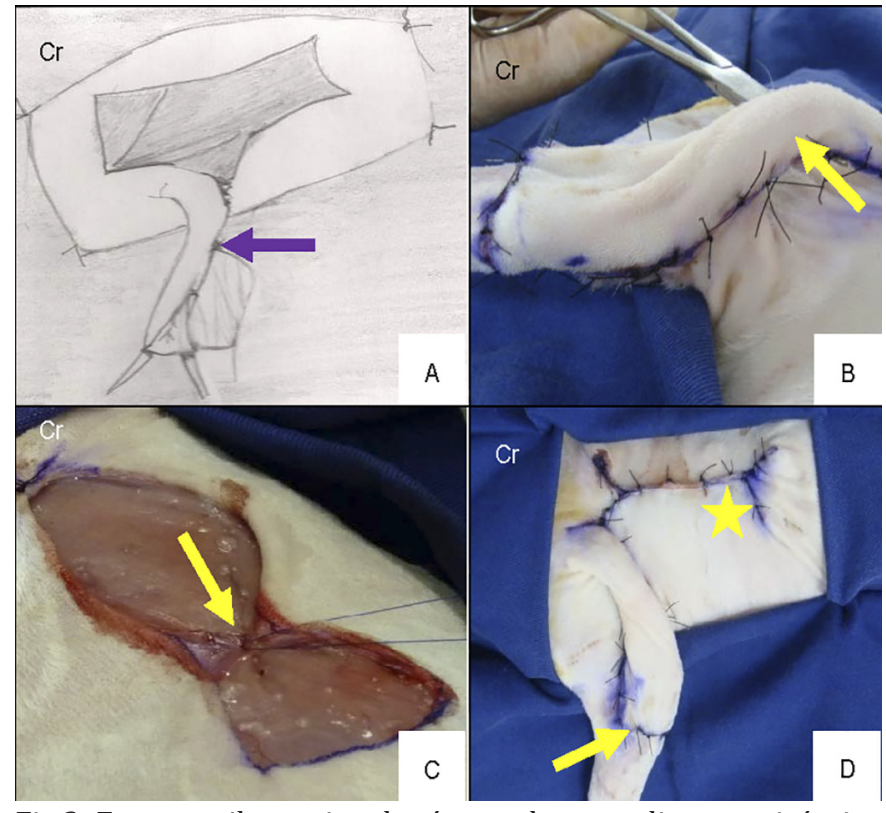

Fig.2. Esquema ilustrativo da síntese do procedimento cirúrgico de reconstrução realizado no Hospital Veterinário da Faculdade de Ciências Agrárias e Veterinárias (FCAV) da Unesp, Campus de Jaboticabal, 2013. (A) Acomodação do flape para o recobrimento da solução de continuidade no cotovelo (seta). (B) Confecção do tubo de comunicação do leito doador com o leito receptor (seta). (C) Redução de espaço morto do leito doador com fio absorvível sintético monofilamentar poliglecaprone 4.0 em padrão "walking suture" (seta). (D) Síntese da ferida cirúrgica com fio inabsorvível náilon 4.0, em padrão simples separado, no leito receptor (seta) e leito doador com padrão Wolf e com fio inabsorvível náilon 4.0 (asterico). 


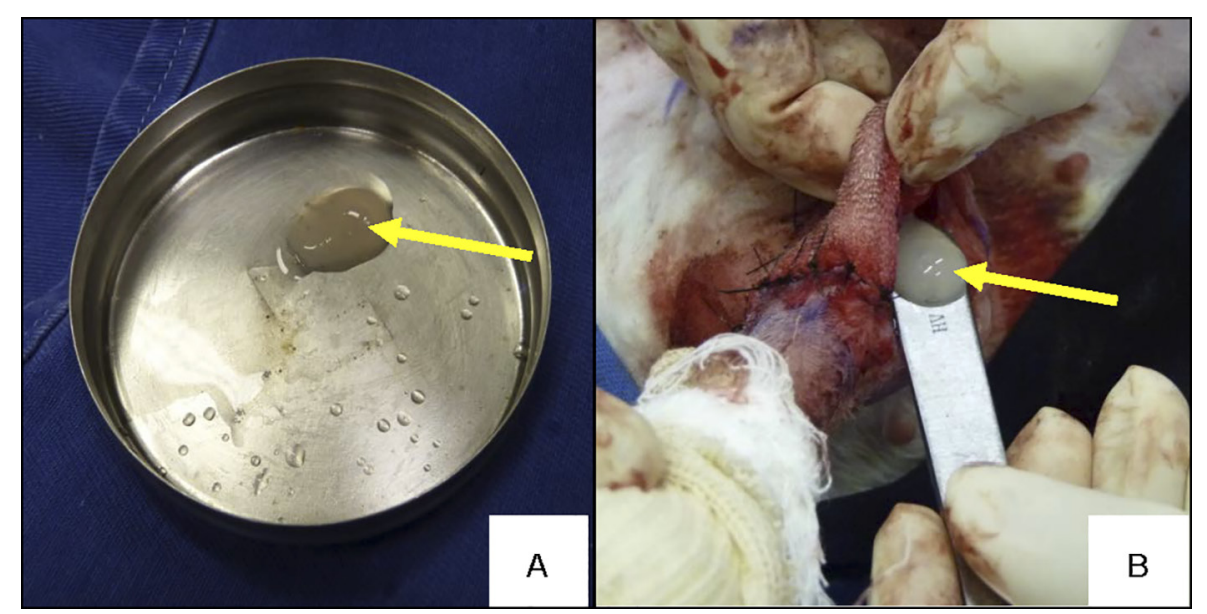

Fig.3. Imagem fotográfica da aplicação do gel de plasma rico em plaquetas em coelhos, confeccionado no Laboratório de Patologia Clínica do Curso de Pós-Graduação em cirurgia Veterinária da Faculdade de Ciências Agrárias e Veterinárias (FCAV) da Unesp, Campus de Jaboticabal, 2013. (A) Gel de plasma rico em plaquetas (seta). (B) Aplicação do plasma rico em plaquetas (seta) na ferida cirúrgica antes da síntese completa.

O gel de plasma rico em plaquetas autólogo $(0,7 \mathrm{~mL}$ de PRP) (Fig.3A) foi colocado no GPRP antes da síntese da lesão no cotovelo com auxílio do cabo de bisturi ${ }^{24}$ e distribuído de maneira homogênea entre o subcutâneo do leito doador e o subcutâneo do leito receptor (Fig.3B), e os animais do GC receberam $0,7 \mathrm{~mL}$ de solução fisiológica ${ }^{2}$. Após aplicação das respectivas soluções procedeu-se a síntese da ferida cirúrgica.

Como protocolo de analgesia, os animais receberam Morfina $^{25}$ na dose de $0,5 \mathrm{mg} / \mathrm{kg}$, por via subcutânea, com intervalos de 12 horas, durante 7 dias, antibiótico terapia com Enrofloxacina $10 \%{ }^{26}$ na quantidade de $0,1 \mathrm{~mL} / \mathrm{kg}$ (diluído em $0,7 \mathrm{~mL}$ de Solução fisiológica), por via subcutânea, com intervalo de 24 horas, durante 10 dias e anti-inflamatório Meloxicam ${ }^{27}$ na dose de $0,1 \mathrm{mg} / \mathrm{kg}$, por via subcutânea, com intervalos de 24 horas, durante 3 dias.

Em todos os animais de ambos os grupos os curativos foram

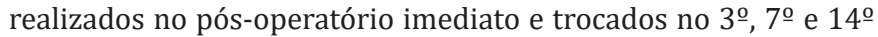
dias, juntamente foram realizadas as avaliações macroscópicas, até a data da eutanásia. A limpeza e troca dos curativos eram conduzidas da seguinte maneira, limpeza da ferida com solução fisiológica $\left(\mathrm{NaCl} 0,9 \%^{2}\right)$, remoção de exsudato quando necessário; cobertura com gaze $\mathrm{e}^{28}$; fixação da gaze com atadura ${ }^{29}$ e esparadrapo $^{30}$.

As avaliações macroscópicas da ferida consistiam em avaliar a presença ou ausência de exsudato, integridade da pele, edema, rubor e necrose. A presença ou não de exsudato, para avaliar a instalação de provável processo inflamatório na ferida cirúrgica, foi avaliado e posteriormente graduado em: 0 ausência de exsudato, 1 discreta presença, 2 moderada presença e 3 intensa presença. A avaliação da integridade da pele consistia em graduar sua coloração, variando de 1 a 3, onde 1 representava pele rósea, 2 hemorragia leve, e 3 hemorragia intensa. Para avaliação do edema utilizou-se a graduação de 0 a 3, sendo 0 ausência de edema, 1 edema discreto, 2 edema moderado e 3 edema intenso. 0 rubor da pele foi graduada em 1 e 2 , sendo 1 ausente e 2 presente. E para avaliação de necrose utilizou-se a graduação de 0 a 1 , sendo ausência de necrose graduado em 0 e necrose presente 1 .

No 15을 dia de pós-operatório, os coelhos foram eutanasiados para colheita de material da avaliação microscópica. A eutanásia foi realizada com propofol, na dose de $10 \mathrm{mg} / \mathrm{kg}$, administrado por via intravenosa, a fim de aprofundar o plano anestésico, ato contínuo realizou-se a infusão de cloreto de potássio, obedecendo-se os princípios éticos em experimentação animal preconizados pelo Conselho Nacional de Experimentação Animal (CONCEA).
Em seguida, as feridas foram excisadas com margem de $1 \mathrm{~cm}$ de pele íntegra em torno da lesão de $16 \mathrm{~cm}^{2}$, e em relação à profundidade a fáscia muscular foi o limite. Dividiu-se o fragmento em três porções distintas, de aproximadamente $1,2 \mathrm{~cm}$ cada uma, as quais eram identificadas em: porção distal, média e proximal para avaliar histologicamente se houve diferença significativa entre elas.

Identificou-se os fragmentos individualmente, fixando-os em cartolina branca, e imersos em solução de formol ${ }^{31}$ a $10 \%$. Após 48 horas a solução que as amostras encontravam-se imersas foi substituída por álcool ${ }^{32}$ a $70 \%$, em seguida encaminhou-se o material fixado em cartolina branca para o Laboratório de Patologia Veterinária VetPat ${ }^{33}$ em Campinas/SP para a confecção das lâminas e posterior avaliação histológica.

As amostras foram processadas conforme a rotina convencional de processamento histológico, com desidratação em diluições crescentes de álcoois e diafanização em xilol ${ }^{34}$, para inclusão em blocos de parafina histológica. Estes foram cortados em micrótomo, com espessura de $4 \mu \mathrm{m}$ e corados pelo método histoquímico de rotina, pela hematoxilina e eosina (HE), para análise em microscopia óptica.

A análise dos cortes histológicos foi realizada pelo mesmo patologista sem o conhecimento prévio da identificação dos grupos. A avaliação histológica das lâminas foi realizada em microscópio óptico ${ }^{35}$ no aumento de 400x. As fotomicrografias foram realizadas no programa Motic Images Plus 2.0. Os dados obtidos foram classificados de acordo com a intensidade em que eram encontrados e transformados em variáveis quantitativas mediante atri-

\footnotetext{
${ }^{24}$ Cabo de bisturi n4 - Brasmed Empresa Brasileira de Cirurgia Veterinária Ltda, Paulínia, SP.

${ }^{25}$ Dimorf, Cristália, Itapira, SP.

${ }^{26}$ Zelotril 10\%, União Química Farmacêutica Nacional S/A, São Paulo, SP.

${ }^{27}$ Maxicam, OuroFino Agronegócios, Cravinhos, SP.

${ }^{28}$ Gaze hidrófila estéril - Herika - América Medical Ltda, Curvelo, MG.

${ }^{29}$ Atadura Cremer, Blumenau, SC.

${ }^{30}$ Esparadrapo, Cremer, Blumenau, SC.

${ }^{31}$ Formol tamponado 10\%, Indaiá Laboratório Farmacêutico Ltada, Dores do Indaiá, $\mathrm{MG}$.

32 Álcool etílico 70\%, Emfal Especialidades Químicas, Betim, MG.

${ }^{33}$ Laboratório de Patologia Veterinária VetPat, Campinas, SP.

${ }^{34}$ Xilol - Quimidrol, Joinville, SC.

${ }^{35}$ Microscópio Nikon eclipse - E200.
} 
buição de índice para o achado histológico, conforme preconizado por Garros et al. (2006) e registrados em fichas individuais para cada animal.

Os dados de PRP (concentração plaquetária) foram analisados pelo teste t emparelhado com grau de significância de 5\%, e também foram analisados descritivamente por meio de gráfico diferenciando as médias dos valores da contagem plaquetária pré e pós enriquecimento do plasma rico em plaquetas (PRP). A comparação entre os grupos (GPRP e GC) em relação às variáveis categóricas (exsudato, integridade da pele, edema, RUBOR, necrose, proliferação vascular, células mononucleares, células polimorfonucleares, proliferação de fibroblasto, colagenização, reepitelização e hemorragia) foi realizado o teste de Kruskal-Wallis (não paramétrico), sendo que para valores de p iguais ou inferiores a 0,05 as diferenças das medianas entre os grupos foram consideradas significativas. Para comparação entre os grupos GC e GPRP em termos de ganho de peso utilizou-se o teste $t$ de Student. Para ambas as análises foi utilizado o procedimento General Linear Models (GLM) do programa computacional SAS (SAS 9.1, SAS Institute, Cary, NC, USA).

\section{RESULTADOS E DISCUSSÃO}

Nas amostras de sangue dos coelhos do GPRP, a contagem inicial de plaquetas apresentava-se dentro dos padrões fisiológicos para a espécie, variando de 290.000 a 678.000 plaquetas $/ \mu \mathrm{L}$. Obteve-se a partir de $7,2 \mathrm{~mL}$ de amostra de sangue total, um volume médio de PRP de $0,7 \mathrm{~mL}$, sendo que a contagem média de plaquetas obtidas após a centrifugação foi de 1.176 .933 plaquetas $/ \mu \mathrm{L}$.

A contagem de plaquetas após o processo de enriquecimento do PRP apresentou-se maior quando comparada com a amostra inicial, com média de 1.176 .933 plaquetas/ $\mu \mathrm{L}$. Os dados obtidos neste ensaio são semelhantes aos resultados encontrados por Silva et al. (2011), visto que em seu estudo a contagem de plaquetas na amostra final, após a o enriquecimento do PRP, foi significativamente maior quando comparado com a amostra de sangue inicial.

Entretanto, alguns autores relatam que a contagem plaquetária deve-se apresentar valores superiores a 1.000.000 plaquetas/ $\mu \mathrm{L}$ (Del Carlo et al. 2009) embora outros autores obtiveram efeitos terapêuticos desejados com concentrações superiores a 300.000 plaquetas/ $\mu \mathrm{l}$ (Carmona et al. 2009, Del Carlo et al. 2009). Assim, os resultados obtidos nesta pesquisa foram condizentes com Carmona et al. (2009) e Del Carlo et al. (2009), em virtude da contagem plaquetária ter variado entre 470.000 a 4.420 .000 plaquetas/ $\mu \mathrm{L}$ no PRP final (desvio padrão $=980.546$ plaquetas / $\mu \mathrm{L}$ ), e alcançou nessas concentrações os efeitos terapêuticos desejados.

0 protocolo da dupla centrifugação foi capaz de promover uma média de concentração plaquetária três vezes maior em relação ao valor inicial da amostra (desvio padrão $=980.546$ plaquetas $/ \mu \mathrm{L}$ ). Na Figura 4 estão apresentadas as médias dos valores de contagem plaquetária pré e pós enriquecimento do plasma rico em plaquetas (PRP). Sendo assim, a amostra final de PRP quando comparada com a inicial foi significativamente maior no grupo PRP $(p=0,006)$.

Nesta pesquisa, o protocolo de centrifugação foi adequado para obtenção de PRP de boa qualidade, semelhante ao descrito por Morato (2013), estudo este que utilizou o

\section{Avaliação do número de plaquetas pré e pós processo de enriquecimento}

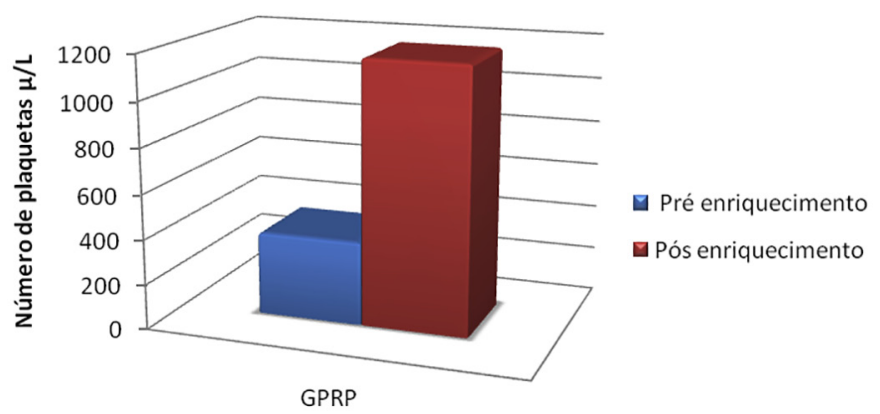

Fig.4. Resultado da centrifugação para obtenção do PRP em coelhos submetidos ao procedimento de cirurgia reconstrutiva no Hospital Veterinário da Faculdade de Ciências Agrárias e Veterinárias (FCAV) da Unesp, Campus de Jaboticabal, 2013, capaz de promover uma média de concentração plaquetária 3 vezes maior em relação ao valor inicial de sangue coletada nos animais do GPRP $(p=0,006)$.

gel de PRP em enxerto ósseo em coelhos, obtido pelo método de dupla centrifugação, com tempos e velocidades semelhantes aos utilizados neste ensaio, proporcionou a obtenção de bons resultados seguindo esse protocolo.

Em relação ao citrato de sódio, utilizado como anticoagulante nesta pesquisa, obteve-se bons resultados quanto ao preparo do PRP. Entretanto, são citados na literatura outros anticoagulantes como solução de citrato de dextrose (Lu et al. 2008) e heparina (Kasten et al. 2008). Nesta pesquisa, optou-se em utilizar citrato de sódio devido sua fácil obtenção, e por adquiri-lo em tubos estéreis, diminuindo a contaminação no momento da colheita. Vanat et al. (2012), testando a modificação de técnica de preparo do plasma rico em plaquetas em cães também utilizaram tubos estéreis contendo citrato de sódio e obtiveram bons resultados livre de contaminação.

Durante todo o período experimental os animais foram acompanhados diariamente, não sendo observado incômodo, apatia, e anorexia em nenhum dos pacientes, e os pesos foram avaliados no $1^{\circ}$ e no $14^{\circ}$ dia de avaliação. Nos dois grupos, em relação ao peso dos coelhos entre o início e o fim do experimento, não houve diferença significativa $(p=0,66)$.

Em ambos os grupos, o peso dos animais entre o início e o fim do experimento, manteve-se estável, evidenciando que os animais se alimentaram adequadamente e o procedimento cirúrgico não provocou resposta orgânica ao trauma que repercutisse no estado geral dos animais. Estes achados foram semelhantes aos de Salgado et al. (2007), após os animais terem sido submetidos a procedimentos cirúrgicos reconstrutivos não apresentaram sinais de desconforto, anorexia e apatia, porém em relação ao peso dos animais encontraram variação significativa entre o início e o fim do experimento nos animais do grupo tratado em relação ao controle, e não utilizaram nenhuma terapia medicamentosa. Embora neste ensaio não se tenha encontrado diferença significativa quanto ao ganho de peso, os animais mantiveram-se bem, não apresentaram sinais de perda de 


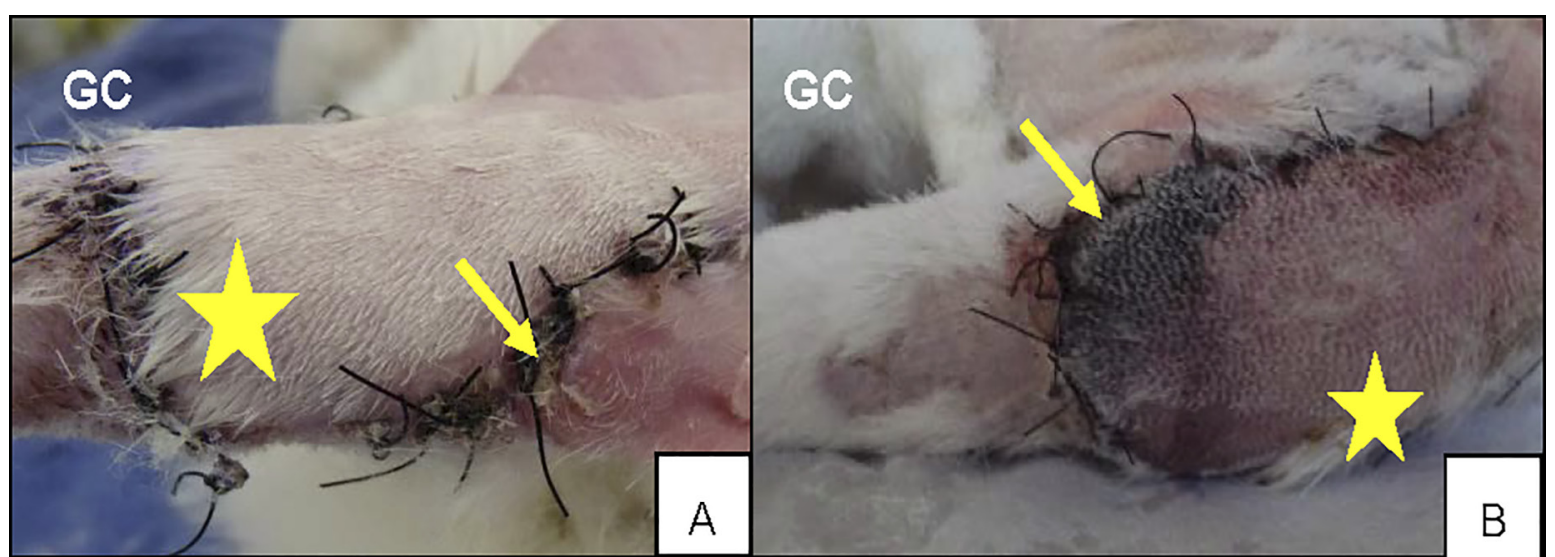

Fig.5. Imagens fotográficas da lesão do cotovelo de coelho (Oryctolagus cuniculus) mostrando as variáveis macroscópicas exsudato com 14 dias que foram significativas entre os grupos $(p<0,05)$ submetidos ao procedimento de cirurgia reconstrutiva no Hospital Veterinário da Faculdade de Ciências Agrárias e Veterinárias (FCAV) da Unesp, Campus de Jaboticabal, 2013. (A) Presença de exsudato (seta) no GC, presença de pelos (asterisco) indicando crescimento após procedimento cirúrgico. (B) Presença de necrose (seta) no GC, presença de pelos (asterisco) indicando crescimento após procedimento cirúrgico.

peso, tampouco outras complicações como anorexia e apatia, e instituiu-se terapia medicamentosa (anti-inflamatório, analgésico e antibiótico).

A avaliação do rubo, edema e integridade da pele, relacionando os grupos GPRP e GC não foram significativas ( $p=0,40 ; p=0,10 ; p=0,47$ respectivamente). Entretanto, as variáveis exsudato (Fig.5A) e necrose (Fig.5B) no GC foram significativamente maiores em relação ao GPRP, sendo $p=0,001$ e $p=0,02$ nesta ordem.

No $3^{\circ}$ dia, as avalições macroscópicas de rubor, integridade da pele, edema e necrose não foram significativas entre os grupos $(p>0,05)$. Porém exsudato apresentou-se significativamente maior no GC quando comparado com GPRP $(p=0,01)$. Nas avaliações do $7^{\circ}$ dia, edema, integridade da pele e necrose não foram significativos entre os grupos $(p>0,05)$. Entretanto, as variáveis exsudato e rubor apresentaram diferença significativa no GC $(p=0,01$ e $p=0,02$ respectivamente) quando comparado com o GPRP. Edema, rubor e necrose no $14^{\circ}$ dia de pós-operatório não foram significativas entre os grupos analisados $(p>0,05)$. No entanto, as variáveis integridade da pele $(p=0,01)$ e exsudato $(p=0,01)$ foram significativas no grupo controle quando comparado com o grupo PRP.

Diante dos resultados obtidos nesta pesquisa quanto as varíáveis macroscópicas, presença de edema não foi significativa entre os grupos, diferentemente dos resultados encontrados por Bauer et al. (2009), que avaliaram os efeitos do plasma rico em plaquetas no processo de reparação de feridas dérmicas em ratos e encontraram 24 horas após o procedimento cirúrgico intensa presença de edema no grupo tratado e controle. Porém é importante saber que os animais utilizados em seu estudo não receberam nenhum tipo de terapia medicamentosa.

Embora não tenha sido observado diferença significativa neste ensaio quanto ao edema, o processo de reparação tecidual seguiu um curso similar ao longo dos períodos observados em ambos os grupos. Nas feridas tratadas com PRP, o edema foi mais expressivo nos três primeiros dias e menor no $14^{\circ}$ dia de pós operatório. Nas feridas tratadas com solução fisiológica o edema foi maior nas primeiras 24 horas e menor no $14^{\circ}$ dia. A presença de edema mais intenso no início do processo de reparação e menor no período final de observação estão condizentes com as descrições de Cotran et al. (1994) e Gregory (1999) que relataram a presença de edema em processo de cicatrização pode ser mais intensa no início, acompanhando os sinais da inflamação (calor, rubor, dor, tumor) e ao final da cicatrização apresenta-se em menor intensidade.

Quanto ao exsudato, essa alteração foi significativamente maior no GC durante as três avaliações. 0 exsudato presente por período prolongado no GC foi devido a inflamação local. No GPRP, exsudato em menor intensidade também foi encontrado, assim pode-se inferir que a aplicação do gel de PRP diminui a produção de exsudato. Entretanto os dados encontrados neste ensaio são contrários aos de Vendramin et al. (2010), os quais estudaram a utilização de PRP autólogo em enxertos cutâneos em coelhos e observaram presença significativa de exsutado relacionado com maior reação inflamatória no grupo com gel de PRP quando comparado com grupo controle, justificando que melhor cicatrização nesse grupo ocorreu pela ação potencializada dos fenomênos decorrentes da fase de inflamação. Porém, Swaim (1980), relata que os componentes relacionados com a fase inflamatória (macrófagos e neutrófilos) favorecem a cicatrização pela ação de enzimas proteolíticas capazes de destruírem bactérias, tecidos necrótico e por serem responsáveis pelo remodelamento da matriz extracelular, e pela produção de tecido de granulação. Entretanto, se for observado inflamação intensa, esse evento será desfavorável para a cicatrização devido a produção de exsudato, presença de edema local e dor, fatores que causam complicações pós cirúrgicas como deiscência de sutura e retardo da cicatrização (Pavletic 2010).

0 rubor esteve presente significativamente maior no $7^{\text {음 }}$ dia no GC. Os resultados encontrados quanto ao rubor foram relacionados diretamente com os sinais da inflamação (calor, rubor, tumor e dor) conforme descrito por Pavletic (2010). Os resultados encontrados nesta pesquisa quanto 
a presença de exsudato e rubor não corroboram com Vendramin et al. (2010), os quais em seu estudo utilizaram PRP autólogo em enxertos cutâneos e a intensidade de exsudato e rubor nos animais que receberam PRP foi maior quando comparado com o grupo controle.

É importante ressaltar que todos os animais que foram submetidos ao procedimento de cirurgia reconstrutiva neste ensaio, receberam no pós-operatório anti-inflamatório, analgésicos e antibióticos, e ainda assim, observou-se presença de reação inflamatória local nos animais do GC. Os resultados obtidos nesta pesquisa quanto a reação inflamatória local e associação de medicação pós-cirúrgicas são contrários aos resultados obtidos por Vendramin et al. (2010) que encontraram presença de reação inflamatória local e não associaram nenhum tipo de terapia medicamentosa nos animais submetidos ao procedimento cirúrgico. Já Morato (2013) em seu estudo avaliando a consolidação de enxertos ósseos com PRP, instituiu análgésico (Cloritrato de Tramadol) e antibiótico (Enrofloxacina 10\%) nos animais submetidos ao procedimento cirúrgico, e não obteve reação inflamatória local. Sendo assim, a utilização de terapia antiinflamatória no pós operatório torna-se questionável, diferentes estudos utilizando o gel de PRP apresentaram resultados opostos quanto ao uso de anti-inflamatórios, porém de acordo com Fossum (2007) e Pavletic (2010) deve-se instituir terapia com anti-inflamatório por no mínimo três dias, antibióticoterapia de no mínimo sete dias e analgesia de no mínimo de 5 dias. Dessa forma, nesta pesquisa, a terapia medicamentosa instituída no pós operatório do procedimento cirúrgico foi conforme o preconizado pela literatura (Fossum 2007, Pavletic 2010).

Visto que ambos os grupos foram submetidos ao mesmo procedimento cirúrgico, diferindo apenas pela aplicação do PRP e solução fisiológica na ferida, e sabendo-se que o flape era constituído de uma artéria e veia, poder-se-ia esperar que complicações relacionadas com comprometimento vascular fossem mínimas, em virtude do leito receptor possuir irrigação adequada, e suturas intradérmicas ou no subcutâneo não terem sido realizadas, a fim de reduzir lesão nos tecidos. No entanto, os resultados no grupo controle foram significativamente maiores quanto a variável necrose $(p=0,02)$, que pode ter ocorrido por situações inadequadas de irrigação sanguínea. Conforme citaram Pavletic (1998) e Fowler (2004) retalhos cutâneos de padrão axial incorporam uma artéria e uma veia cutânea direta, o que proporciona irrigação sanguínea com área de sobrevida aproximadamente $50 \%$ maior que retalhos de plexos subdérmicos em cães, no entanto, alertam que utilização de suturas intradérmicas e no subcutâneo podem predispor a ocorrência de necrose, em virtude de provocarem maior lesão no tecido, prejudicando a irrigação local e angiogênese, porém indicam que em casos que as suturas intradérmicas ou subcutâneas sejam indispensáveis, a melhor opção é a aplicação de bandagem compressiva.

Outros autores citam que embora os flapes de padrão axial sejam melhores por serem calibrosos, complicações podem surgir, como drenagem de secreção purulenta da ferida, deiscência parcial de sutura, necrose distal do retalho, infecções e formação de seroma (Slatter 2007). Os resulta- dos encontrados neste ensaio, quanto à variável necrose, indicam que o GC apresentou complicações provenientes do comprometimento vascular do flape, visto que nenhum dos animais apresentou deiscência de pontos, infecção e formação de seroma. Também não se utilizou suturas no subcutâneo que pudessem comprometer à irrigação local. Sendo assim, pode-se inferir que a necrose esteve presente em virtude de não ter ocorrido neo-angiogênese de maneira adequada no grupo controle conforme descrito na literatura (Fowler 2004, Pavletic 2010).

Quanto a coloração rosada nos flapes que receberam o PRP caracteriza a presença de elementos hemáticos (hemácias, leucócitos e plaquetas) nos vasos do leito receptor. Atribui-se tais caracteristícas uso do gel de PRP sendo capaz de favorecer a microcirculação local. Este achado corrobora as evidências de Vendramin et al. (2006) que relatam uso do PRP em enxertos cutâneos em membro pélvico de humanos sendo capaz de reduzir o tamanho da lesão, promovendo maior quantidade de tecido de granulação e apresentando aspecto rosado da pele quando comparado com pacientes que não receberam o produto. Dessa forma, pode-se presumir que a utilização do PRP resultou em melhor coloração neste grupo, relacionando assim com os aspectos macroscópicos de integridade da pele, ou seja, a pele ficou rósea (100\%) quando comparado com o grupo controle (66\%), no qual foi observada a presença de hemorragia discreta (20\%) e hemorragia intensa (14\%).

A avaliação histológica da intensidade de proliferação vascular foi significativamente maior $(p=0,001)$ no GPRP (Fig.6A), quando comparado com o GC (Fig.6B). A proliferação vascular obteve índice de proliferação maior na porção distal relacionada com as demais porções. $(p=0,01)$. 0 emprego do gel de plasma rico em plaquetas no subcutâneo do leito receptor da ferida no GPRP proporcionou bons resultados, quando comparado com a solução fisiológica no GC, indicando que a diferença significativa encontrada quanto à proliferação vascular está relacionada com o uso do PRP, sugerindo a capacidade deste composto de promover angiogênese no local de aplicação.

Avaliando a intensa proliferação vascular nos animais tratados com PRP pode-se correlacionar tal fato com os fatores de crescimento presentes nas plaquetas, responsáveis em atuar na fase inicial da cicatrização. Dentre os inúmeros fatores de crescimento, o fator de crescimento de endotélio vascular (VEGF) e fator de crescimento epitelial (EGF) estimulam a angiogênese, mitogênese, permeabilidade vascular, e induzem crescimento de tecido epitelial (Bolta 2007). Os resultados encontrados neste ensaio indicaram que a proliferação vascular ocorreu principalmente pelos fatores presentes nas plaquetas, assim, promoveram o suprimento de oxigênio e nutrição da ferida, favorecendo o processo cicatricial.

A formação de novos vasos parece ser substancialmente favorecida pela aplicação do gel de PRP, o número relativamente maior de elementos de pequeno e médio calibre é observado no GPRP. Esse fato evidencia que o plasma rico em plaquetas é capaz de estimular a proliferação vascular no leito receptor da ferida e reduz as taxas de necrose por aumentar a irrigação local no leitor receptor, fazendo-se 


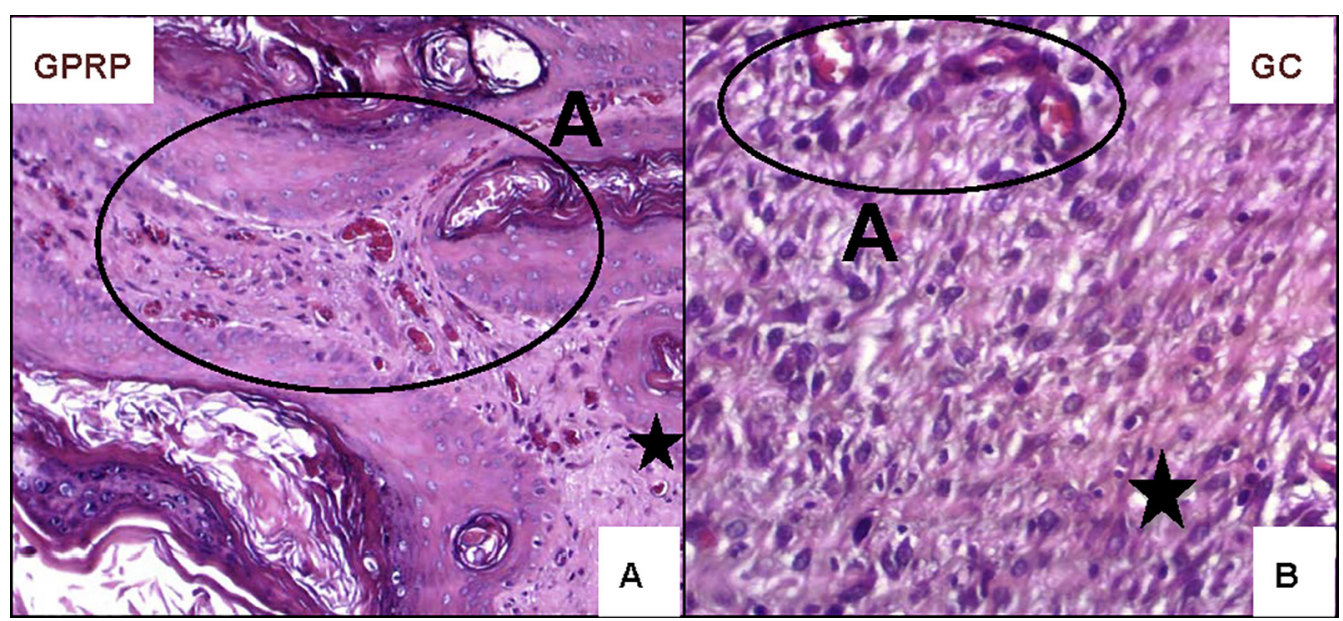

Fig.6. Aspecto histológico da Intensidade de proliferação vascular em coelhos (Oryctolagus cuniculus). Fotomicrografia óptica da porção distal derme de animais do GPRP e GC submetidos ao procedimento de cirurgia reconstrutiva no Hospital Veterinário da Faculdade de Ciências Agrárias e Veterinárias (FCAV) da Unesp, Campus de Jaboticabal, 2013. Derme superficial (asterisco) dos animais do GC e GPRP após 15 dias da aplicação da solução fisiológica e Gel de PRP. (A) Notar presença acentuada de neovascularização em A no GPRP, aumento de 200x. (B) Notar presença discreta de neovascularização em A no GC. Coloração HE, aumento de 400x.

alusão com os efeitos do PRP obtidos por Vendramin et al. (2006) que testaram a aplicação do produto em enxertos cutâneos, ósseos e na cicatrização de feridas, observando diminuição no tamanho das feridas, bem como o desenvolvimento de um tecido de granulação de melhor qualidade, com uma vascularização mais intensa.

Quanto à reação inflamatória da ferida avaliou-se a presença das células mononucleares e polimorfonucleares (macrófagos e neutrófilos), porém não foram observadas diferenças significativas ( $p=0,65$ e $p=0,14$, respectivamente) entre os grupos experimentais. Em relação à reação inflamatória da ferida cirúrgica, avaliou-se a presença das células mononucleares e polimorfonucleares (macrófagos e neutrófilos), porém não houve diferença significativa entre os grupos experimentais. Os resultados encontrados neste ensaio são semelhantes ao obtidos por Vendramin et al. (2010), que embora no seu estudo tenham utilizando o plasma rico em plaquetas autólogo em enxertos cutâneos em coelhos, observaram presença de infiltrado inflamatório nos cortes histológicos, porém as variáveis categóricas não demonstraram diferença estatisticamente significativa.

Portanto, a presença discreta de mononucleares e polimorfonucleares podem ser justificadas pelo tempo de evolução da ferida (14 dias). Os resultados encontrados neste ensaio foram semelhantes ao obtidos por Bauer et al. (2009), que avaliando efeitos do plasma rico em plaquetas no processo de reparação de feridas dérmicas em ratos encontrou 24 horas após procedimento cirúrgico presença intensa de neutrófilos, e após três dias intensa presença de macrófagos, e após sete dias número intenso de fibroblastos. Correlacionando os achados encontrados neste ensaio com as fases da inflamação, sabe-se que logo após a ocorrência da lesão são recrutados polimorfonucleados para realizarem fagocitose das bactérias, decomposição de tecido necrótico e promover a limpeza da ferida, em seguida, por meio de fatores quimiotáticos recrutam-se os macrófagos, que atuam na remodelação da matriz extracelu- lar, e também liberam substâncias vasoativas e fatores de crescimento para auxiliar nas fases subsequentes da inflamação (Rodrigues et al. 2001, Cândido 2007, Slatter 2007). 0 estudo histológico comprovou que, mesmo não havendo diferença significativa entre as variáveis categóricas de presença de células mononucleares e polimorfonucleares, foi possível visibilizar na microscopia óptica que houve discreta reação inflamatória local com uso do PRP, que pode ter potencializado a reparação.

Quando se avaliou intensidade de proliferação de fibroblastos $(p=0,52)$, colagenização $(p=0,87)$ e hemorragia $(p=1,0)$ os resultados foram semelhantes entre os grupos experimentais, não apresentando diferenças significativas.

0 aumento no número de macrófagos e fibroblastos era esperado pelo efeito de quimiotaxia e dos fatores de crescimento, porém não foi significativo entre os grupos, mas foi visível nas lâminas. A maior quantidade de colágeno (colágeno imaturo) também observada foi devido ao estímulo dos fibroblastos pelos fatores de crescimento. Os achados deste ensaio são semelhantes aos de Liu et al. (2002), que mostraram aumento da produção de macrófagos, proliferação de fibroblastos e colágeno são proporcionais ao aumento da concentração plaquetária no PRP. Bhanot et al. (2002) e Man et al. (2001), também relataram que o PRP aumenta a taxa de produção de colágeno, angiogênese, proliferação de fibroblastos e síntese de matriz extracelular, melhorando a reparação de modo geral.

Quanto à hemorragia, os achados microscópicos indicaram discreta presença de hemorragia em ambos os grupos, sendo em alguns momentos mais intensa nos animais do GPRP. Pode-se inferir que em virtude da estimulação da angiogênese promovida pelo gel de PRP formando novos capilares de pequeno e médio calibre acabem sendo rompidos por serem frágeis, promovendo hemorragia local. Por outro lado, os animais do GC apresentaram hemorragia e vasos congestos, fato que pode ser correlacionado com os achados macroscópico quanto a presença de rubor no GC. 
Os resultados encontrados nesta pesquisa, são condizentes com os de Vendramin et al. (2006) e Bauer et al. (2009), utilizando PRP em enxertos ósseos e avaliando os efeitos do plasma rico em plaquetas no processo de reparação de feridas dérmicas em ratos, não sendo observada a presença significativa de hemorragia nos grupos experimentais.

A intensidade da re-epitelização no GPRP quando comparado com o GC foi significativa $(p=0,01)$. No GPRP a reepitelização foi significativamente maior $(p=0,009)$ na região distal quando comparada com as outras regiões (Fig.7). A reepitelização, caracterizada pelo aumento das camadas epiteliais foi significativamente maior no GPRP. Ocorreu de maneira mais acentuada na porção distal da lâmina quando comparada com as outras porções. Sendo assim, a boa resposta vascular mediante aplicação do gel de plasma rico em plaquetas é considerada como fator positivo na reepitelização, visto que ocorreu de maneira progressiva, devido a nutrição sanguínea da ferida ter sido adequada. A reepitelização intensa presente nos animais do grupo PRP estão condizentes com Bauer et al. (2009), em seu estudo avaliando os efeitos do plasma rico em plaquetas no processo de reparação de feridas dérmicas padronizadas em ratos encontrou maior reepitelização após 7 dias do procedimento cirúrgico nos animais tratados com o PRP.

Diante dos resultados encontrados neste ensaio, é importante ressaltar a semelhança entre a microscópica e a macroscópica quanto à presença de necrose nas lesões do GC, o qual apresentou diferença significativamente maior quando comparada com GPRP. Conforme descrito por Bauer et al. (2009), existem casos que 24 horas e três dias após procedimento cirúrgico pode-se visualizar tecido necrótico superficial na epiderme e derme, e acima de sete dias tecido necrótico. Sendo assim, os resultados obtidos neste estudo, são condizentes com a literatura, como as lâminas foram confeccionadas com material correspondente ao décimo quarto dia do pós-operatório pode-se correlacionar os achados macroscópico com os microscópicos.

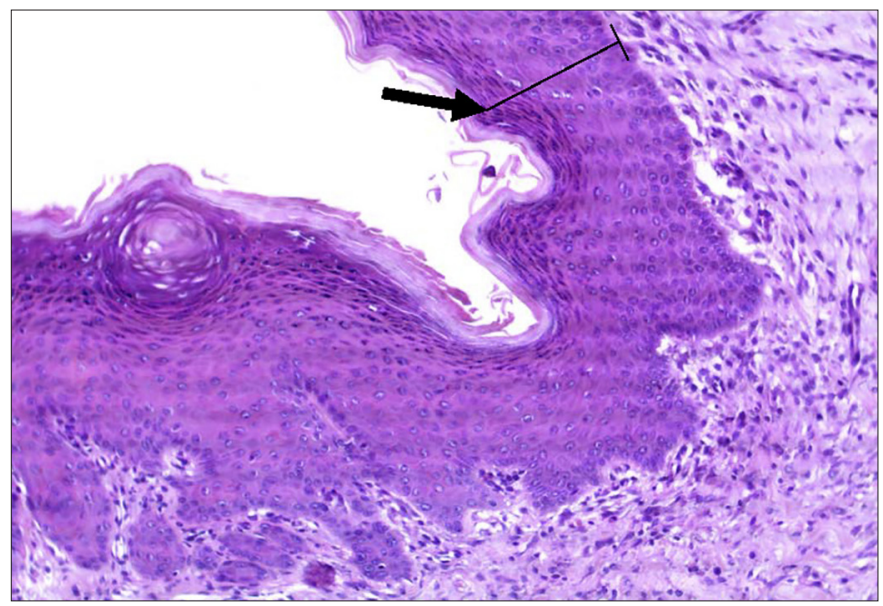

Fig.7. Aspecto histológico da intensidade de reepitelização em coelhos (Oryctolagus cuniculus). Porção distal da derme de animais do GPRP $(\mathrm{p}=0,009)$ submetidos ao procedimento de cirurgia reconstrutiva no Hospital Veterinário da Faculdade de Ciências Agrárias e Veterinárias (FCAV) da Unesp, Campus de Jaboticabal, 2013. Notar presença acentuada de reepitelização (seta). HE, 200x.

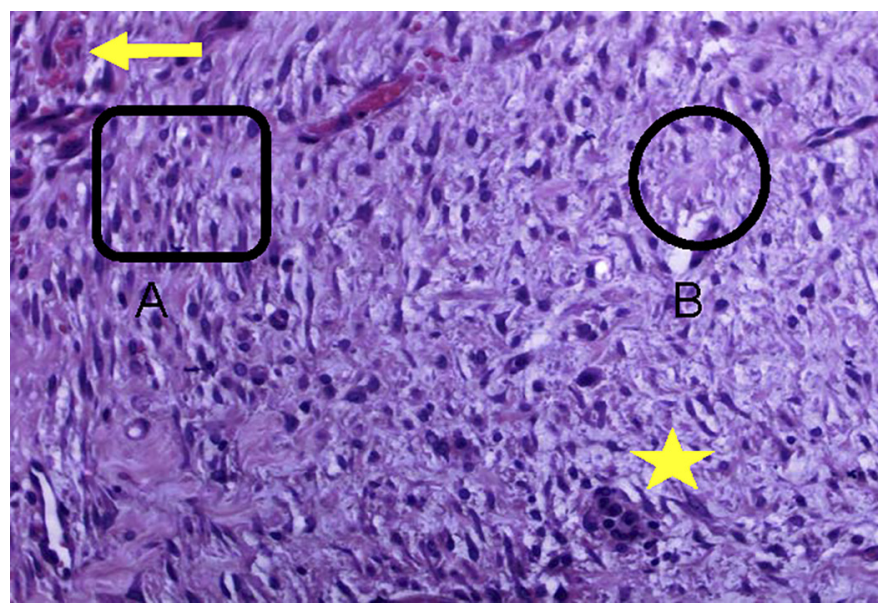

Fig.8. Aspecto histológico de necrose em coelhos (Oryctolagus cuniculus). Fotomicrografia óptica da derme de animais do GC submetidos ao procedimento de cirurgia reconstrutiva no Hospital Veterinário da Faculdade de Ciências Agrárias e Veterinárias (FCAV) da Unesp, Campus de Jaboticabal, 2013. Notar presença discreta de hemorragia (seta). Presença de fibroblastos em picnose em A. Ausência de colágeno em B e presença de mononucleares (asterisco). HE, 200x.

Observou-se neste estudo, as lâminas dos animais do GC com presença de tecido necrótico na região da epiderme, com fibroblastos em picnose, e áreas com destruição de colágeno (Fig.8) em derme. Durante o processo de necrose ocorre morte celular de um organismo vivo. As principais causas da ocorrência de necrose no epitélio são obstrução vascular por isquemia (coloração esbranquiçada) e anóxia (coloração vermelho escuro). As principais alterações decorrentes do processo de autólise podem ser visualizadas à microscopia algum tempo após ter ocorrido a morte celular. Os achados encontrados podem ser picnose nuclear (intensa contração e condensação de cromatina, tornando o núcleo intensamente basófilo, de aspecto homogêneo e bem menor que o normal), cariólise (digestão da cromatina, com desaparecimento da afinidade tintorial do núcleo, a ponto de não ser identificado em coloração de rotina) e cariorrexe (fragmentação e dispersão do núcleo no citoplasma) (Brasileiro Filho 2011). Os resultados encontrados neste ensaio são condizentes com a literatura, a presença de tecido necrótico observado nas lâminas apresentava áreas com destruição de colágeno e fibroblastos com núcleo picnótico, lesões características de presença de necrose tecidual.

\section{CONCLUSÕES}

Os resultados obtidos neste estudo evidenciaram que a utilização do plasma rico em plaquetas na forma de gel em cirurgia reconstrutiva é capaz de estimular a angiogênese na ferida favorecendo o processo de cicatrização.

0 gel de PRP é capaz de reduzir a ocorrência de necrose na extremidade dos flapes, e favorece a fase de reparação e integração do retalho no leito receptor.

A utilização do plasma rico em plaquetas é uma boa opção em cirurgias reconstrutivas, por reduzir complicações decorrentes do procedimento cirúrgico. 
Agradecimentos.- Ao mestrando Romeu dos Santos pelas contribuições nas análises histopatológicas, à Faculdade de Ciências Agrárias e Veterinárias, Unesp, Campus Jaboticabal, SP, e à Coordenação de Aperfeiçoamento de Pessoal de Nível Superior (CAPES), pela concessão de bolsa de mestrado.

\section{REFERÊNCIAS}

Anitua E. 1999. Plasma rich in growth factors: preliminary results of use the preparation of sites for implants. Int. J. Oral Maxil. Impl. 14(4):529535.

Bauer J.A., Correa J., Lima M.F.L., Lima L.A.P.A. \& Pustiglioni F.E. 2009. Efeitos do plasma rico em plaquetas no processo de reparação de feridas dérmicas padronizadas em ratos. Revta Periodontia 19(3):98-108.

Bhanot D. \& Alex J.C. 2002. Current applications of platelet gels in facial plastic surgery. Fac. Plast. Surg. 18(1):27-33.

Bolta P.R.Z. 2007. Use of platelet growth factors in treating wounds and soft-tissue injuries. Acta Dermatovenerologica Alpina, Pannonica et Adriatica 16(4):156-165.

Brasileiro Filho G. 2011. Adaptação, dano e morte celular, p.10-30. In: Bogliolo L. (Ed.), Patologia Geral. 8ª ed. Guanabara Koogan, Rio de Janeiro.

Cândido L.C. 2007. Nova Abordagem no Tratamento de Feridas. Editora Senac, São Paulo. 282p.

Carmona J.U., López C. \& Prades M. 2009. Uso de concentrados autólogos de plaquetas obtenidos mediante el método del tubo como tratamiento de artopatías em caballos. Archs Med. Vet. 41:175-176.

Cotran R.S., Kumar V. \& Robbins S.L. 1994. Information and repair, p.85-88. In: Cotran R.S., Kumar V. \& Robbins S.L. (Eds), Pathologic Basis of Diseases. 5th ed. W.B. Saunders, Philadelphia.

Del Carlo R.J., Monteiro B.S., Silva Argolo N. \& Serakides R. 2009. Aspectos microscópicos da reparação mediada por plasma rico em plaquetas e auto enxerto esponjoso em falhas ósseas experimentais no crânio de coelhos. Vet. Zootec. 16(1):152-160.

Fossum T.W. 2007. Cirurgias reconstrutivas do sistema tegumentar, p.135186. In: Fossum T.W. (Ed.), Cirurgia de Pequenos Animais. $3^{3}$ ed. Roca, São Paulo.

Fowler D. 2004. Retalhos de pele, p.98-101. In: Harara J. (Ed.), Segredos em Cirurgia de Pequenos Animais. 2 ${ }^{\underline{a}}$ ed. Artmed, Porto Alegre.

Garcez T.N.A., Paz A.H.R., Magrisso A.B., Mello H.F., Gonçalves F.C., Meyer F.S., Contesini E.A. \& Lima E.O.C. 2013. Comparação entre três protocolos de obtenção de plasma rico em plaquetas (prp) utilizando coelho como modelo experimental. Acta Scient. Vet. 41:1-7.

Garros I.C., Campos A.C., Lâmbara E.M., Tenório S.B., Torres O.J.M., Agulham M.A., Araújo A.C.F., Isolan P.M.B.S., Oliveira R.M. \& Arruda E.C.M. 2006. Extrato de Passiflora edulis na cicatrização de feridas cutâneas abertas em ratos: estudo morfológico e histológico. Acta Cir. Bras. 21(3):55-65.

Gregory C.R. 1999. Wound healing and influencing factors, p.13-24. In: Fowler D. \& Williams J.M. (Eds), Manual of Canine and Feline Wound Management and Reconstruction. British Small Animal Veterinary Association, England.

Hedlund C.S. 2005. Cirurgia do Sistema tegumentar, p.135-230. In: Fossum T.W. (Ed.), Cirurgia de Pequenos Animais. $2^{\underline{a}}$ ed. Roca, São Paulo.

Kasten P., Vogel J., Geiger F., Niemeyer P., Luginbühl R. \& Szalav K. 2008. The effect of platelet-rich plasma on healing in critical size long bone defects. Biomaterials 29(29):3983-3992.

Liu Y., Kalén A., Risto O. \& Wahlström 0. 2002. Fibroblast proliferation due to exposure to a platelet concentrate in vitro is ph dependent. Wound Repair Regeneration 10(5):336-340.
Lu H., VO J.M., Chin H.S., Lin J., Cozin M., Tsay R., Eisig S. \& Landesberg R. 2008. Controlled delivery of platelet rich plasma derived growth factors for bone formation. J. Biomed. Materials Res. A 86(4):1128-1136.

Man D., Plosker H. \& Winland Brown J.E. 2001. The use of autologous platelet rich plasma (platelet gel) and autologous platelet-poor plasma (fibrin glue) in cosmetic surgery. Plastic Reconstr. Surg. 107(1):229-237.

Morato G.O. 2013. Osso esponjoso liofilizado de cão utilizado como enxerto puro e associado a plasma rico em plaquetas ou medula óssea em falhas ósseas induzidas em coelhos: estudo experimental. Dissertação de Mestrado em Cirurgia Veterinária, Faculdade de Ciências Agrárias e Veterinárias, Universidade Estadual Paulista Júlio de Mesquita Filho, Jaboticabal, SP. 80p.

Nunes Filho D.P., Luppino F., Yaedú R.Y.F. \& Carvalho P.S.P. 2007. Avaliação microscópica da ação do osso autógeno associado ou não ao prp em cavidades ósseas de cães. Rev. Implante News 4(3):263-262.

Pagliosa G.M. \& Alves G.E.S. 2007. Considerações sobre a obtenção e o uso do plasma rico em plaquetas e das células mesenquimais indiferenciadas em enxertos ósseos. Ciência Rural 37(4):1202-1205.

Pavletic M.M. 1998. Pele e órgãos anexos, p.323-333. In: Slatter D. (Ed.), Manual de Cirurgia de Pequenos Animais. Vol.2. 3a ed. Manole, São Paulo.

Pavletic M.M. 2007. Tegumento, p.292-321. In: Slatter D. (Ed.), Manual de Cirurgia de Pequenos Animais. Vol.1. 3ํㅗ ed. Manole, São Paulo.

Pavletic M.M. 2010. Small Animal Wound Management and Reconstructive Surgery. 3rd ed. Wiley-Blackwell, Iowa, p.357-378.

Rodrigues F.R., Cândido I.C., Assad L.G., Costa M.C.A. \& Coutinho V.L. 2001. Curativos em cirurgia, p.359-374. In: Marques R.G. (Ed.), Cirurgia Instrumental e Fundamentos Técnicos. Cultura Médica, Rio de Janeiro.

Salgado M.I., Pretoianu A., Burgarelli G.L., Barbosa A.J.A. \& Alberti L.R. 2007. Cicatrização conduzida e enxerto de pele parcial no tratamento de feridas. Revta Assoc. Méd. Bras. 53(1):80-84.

Silva F.R., Rezende C.M.F., Paes-leme F.0. \& Carmona J.U. 2011. Evaluación del método del tubo para concentrar plaquetas caninas: estudio celular. Archs. Med.Vet., Valdivia, 43:95-98.

Slater D. 2007. Manual de Cirurgia de Pequenos Animais: pele e órgãos anexos. 3aㅡ. ed. Manole, São Paulo, p.304-309.

Sommeling C.E., Heyneman A., Hoeksema H., Verbelen J., Stillaert F.B. \& Monstrey S. 2013. The use of platelet rich plasma in plastic surgery: a systematic review. J. Plastic Reconstructive and Aesthetic Surgery 66:301-312.

Swaim S.F. 1980. Wound healing, p.48-62. In: Swaim S.S. (Ed.), Surgery of Traumatized Skin: management and reconstruction in the dog and cat. W.B. Saunders, Philadelphia, 585p.

Vanat N., Medeiros T.N.S., Balarin M.R.S., Pereira P.M. \& De Biasi F. 2012. Modificação de técnica de preparo do plasma rico em plaquetas em cães. Semina, Ciênc. Agrárias 33(1):313-322.

Vendramin F.S., Franco D., Nogueira C.M., Pereira M.S. \& Franco T.R. 2006. Plasma rico em plaquetas e fatores de crescimento: técnica de preparo e utilização em cirurgia plástica. Revta Colégio Bras. Cirur. 33(1):24-28.

Vendramin F.S., Franco D., Schamall R.F. \& Franco T.R. 2010. Utilização do plasma rico em plaquetas (prp) autólogo em enxertos cutâneos em coelho. Revta Bras. Cir. Plástica 25:4-10.

Vendruscolo C.P., Carvalho A.M., Moraes I.F., Maia I., Queiroz D.L., Watanabe M.J., Yamada A.L.M. \& Alves A.L.G. 2012. Avaliação da eficácia de diferentes protocolos de preparo do plasma rico em plaquetas para uso em medicina equina. Pesq. Vet. Bras. 32(2):106-110. 